\title{
jy-

Título artículo / Títol article:

Effects of green space spatial pattern on land surface temperature: Implications for sustainable urban planning and climate change adaptation

\section{Autores / Autors}

Maimaitiyiming, Matthew ; Ghulam, Abduwasit ; Tiyip, Tashpolat ; Pla Bañón, Filiberto ; Latorre Carmona, Pedro ; Halik, Ümüt ; Sawu, Mamat ; Caetano, Mario

\section{Revista:}

ISPRS Journal of Photogrammetry and Remote Sensing

\section{Versión / Versió:}

Postprint

Cita bibliográfica / Cita bibliogràfica (ISO 690):

MAIMAITIYIMING, Matthew, et al. Effects of green space spatial pattern on land surface temperature: Implications for sustainable urban planning and climate change adaptation. ISPRS Journal of Photogrammetry and Remote Sensing, 2014, vol. 89, p. 59-66.

url Repositori UJI:

http://hdl.handle.net/10234/135506 

3

$9{ }^{\mathrm{b}}$ College of Resources and Environmental Sciences, Xinjiang University, Urumqi, Xinjiang 10830046, China

11 16 17 18 19 20

\section{Effects of green space spatial pattern on land surface temperature:}

\section{implications for sustainable urban planning and climate change adaptation}

${ }^{a}$ Center for sustainability, Saint Louis University, Saint Louis, MO 63103, USA

\author{
Latorre-Carmona $^{\mathrm{d}}$, Mário Caetano ${ }^{\mathrm{e}}$, Mamat Sawut ${ }^{\mathrm{a}, \mathrm{b}, \mathrm{c}}$, Ümüt Halik ${ }^{\mathrm{b}, \mathrm{c}}$
}

${ }^{\mathrm{c}}$ Ministry of Education Key Laboratory of Oasis Ecology at Xinjiang University, Urumqi,

Xinjiang 830046, China

${ }^{\mathrm{d}}$ Institute of New Imaging Technologies, University Jaume I, 12071 Castellón, Spain

7 e Institute for Statistics and Information Management (ISEGI), Universidade Nova de Lisboa, Campus de Campolide, 1070-312, Lisboa, Portugal

1 Abstract - The urban heat island (UHI) refers to the phenomenon of higher atmospheric and surface temperatures occurring in urban areas than in the surrounding rural areas. Mitigation of the UHI effects via the configuration of green spaces and sustainable design of urban 
24 environments has become an issue of increasing concern under changing climate. In this paper, 25 the effects of the composition and configuration of green space on land surface temperatures 26 (LST) were explored using landscape metrics including percentage of landscape (PLAND), edge 


\section{Introduction}

The urban heat island (UHI) refers to the phenomenon of higher atmospheric and surface temperatures occurring in urban areas than in the surrounding rural areas. This phenomenon is widely observed in cities regardless of their sizes and locations (Connors et al., 2013; Cui and de Foy, 2012; Imhoff et al., 2010; Li et al., 2012; Tran et al., 2006). The UHI is mainly caused by the modification of land surfaces by urban development, which uses materials that effectively store short-wave radiation (Solecki et al., 2005). As the result, land surface temperature (LST) increases due to the UHI, which may disrupt species composition and distribution (Niemelä, 1999) by increasing the length of growing seasons, decrease air quality (Feizizadeh and Blaschke, 2013; Lai and Cheng, 2009; Sarrat et al., 2006; Weng and Yang, 2006), leading to greater health risks (Patz et al., 2005). The UHI may also decrease water quality as warmer waters flow into streams putting additional stress on aquatic ecosystems (James, 2002). Therefore, it has become a major research focus in urban climatology and urban ecology since first reported in 1818 (Howard, 1818).

The intensity and spatial pattern of UHI are largely exacerbated from population dynamics and development of build-up areas (Arnfield, 2003; Wu et al., 2013). Specifically, urban structure (e.g. height-to-width ratio of buildings and streets), , proportion of built-up versus green spaces per unit area, weather conditions (e.g. wind and humidity), and socioeconomic activities determine the development of the UHI (Hamdi and Schayes, 2007; Rizwan et al., 2008b; Taha, 1997; Unger, 2004; Voogt and Oke, 1998). For example, Huang et al. (2011) found statistically significant relationship between the UHI and socioeconomic factors indicating that a higher UHI effects were linked to block groups characterized by low income, high poverty, less education, more ethnic minorities, more elderly people and greater risk of 
crime. As many of these factors, especially land surface characteristics are primarily represented by land-cover and land-use (LCLU), the relationship between the LST and LCLU has been the focus of numerous studies on the UHI (Buyantuyev and Wu, 2010; Dousset and Gourmelon, 2003; Pu et al., 2006; Voogt and Oke, 2003;Weng et al., 2004). This is due to the fact that vegetation usually has higher evapotranspiration and lower emissivity than built-up areas, and thus has lower surface temperatures (Hamada and Ohta, 2010; Weng et al., 2004).

Composition and configuration of green spaces are the two major elements of LCLU. The former refers to the abundance and variety of land cover types and the latter is related to the spatial arrangements and layout of land cover types (Connors et al., 2013; Turner, 2005). Remarkable proliferations of studies focusing on the relationship between LST and green space composition has been reported over the last two decades (Chen et al., 2006; Tran et al., 2006; Voogt and Oke, 2003; Weng, 2009; Weng et al., 2004). Though the magnitude of correlations varied among these reports, a negative relationship between the vegetation amount/fraction and LST was consistently observed. However, the spatial characteristics and configurations of vegetation patches within the urban environment have significant impacts on the distribution of the UHI (Bowler et al., 2010; Cao et al., 2010; Honjo and Takakura, 1991; Yokohari et al., 1997; Zhao et al., 2011), and that the size and shape of a vegetation patch creates cool island effects, a phenomenon that the temperature of green space is lower than its surrounding areas (Cao et al., 2010; Zhang et al., 2009). Based on a case study of a heavily urbanized Beijing metropolitan area in China, Li et al. (2012) also indicated that increasing patch density results in significantly higher LST when the size of urban green space unaffected, and that spatial configuration has a significant influence in the variability of derived LST. 
It is evident from an exhaustive literature review hitherto that there is a lack of case studies within arid regions (Connors et al., 2013). As cities are growing fast in population, and urbanization is projected to be high (Baker et al. 2004), sustainable planning of urban environment to mitigate UHI effects highlights a pressing need for immediate attention. This is further emphasized by climate changes as arid regions are likely to become even drier in response to increasing temperature from global warming (Durack et al., 2012). Driven by fast economic growth and population increase, Northwestern China has experienced rapid urbanization in the past several decades, along with a drastic transformation of the urban environment and social equity (Fan and Qi, 2010; Halik et al., 2013; Liu et al., 2013). In addition, the majority of the previous studies used ordinary least squares regression and/or spatial autoregression to analyze the relationship between the landscape metrics and LST. The statistical significance of the relationship between the landscape metrics and LST varied between the methods (Li et al., 2012). Comparative approaches with additional case studies are needed to generalize the methods and concepts demonstrated by these preliminary attempts. To that end, we investigate the effects of composition and configuration of urban green space on LST using a robust moving window algorithm of normalized mutual information measure in the arid city of Aksu, Xinjiang Uyghur Autonomous Region in Northwestern China. One of the advantages of using mutual information measures is that it can capture linear as well as strongly non-linear relationships among variables under the "umbrella" of just one concept ("mutual information"). The goal is to provide guiding suggestions for sustainable urban planning and development under future climate changes. We chose to use Landsat $30 \mathrm{~m}$ resolution data as previous studies (Liu and Weng, 2009; Li et al., 2013) have demonstrated that $30 \mathrm{~m}$ and $90 \mathrm{~m}$ are the optimal 
resolutions to study the relationship between LST and landscape patterns at patch level and landscape levels, respectively.

116 The paper is organized in the sections below. Following the description of the study area in 117 Section 2, the methodology of calculating LST, landscape metrics, and a brief introduction to 118 normalized mutual information measure are presented in Section 3. The results, discussions and 119 conclusions are presented in Section 4, 5 and 6, respectively.

\section{Study area}

The study area, downtown Aksu City, Northwestern China, is a typical oasis city located in an arid region. Aksu City is the capital of Aksu Prefecture in Xinjiang Uyghur Autonomous Region, China. Geographically, the city is situated in south of the Tianshan Mountains and northwest edge of the Tarim Basin $\left(39^{\circ} 30^{\prime} \mathrm{N}-41^{\circ} 27^{\prime} \mathrm{N}, 7^{\circ} 39^{\prime} \mathrm{E}-82^{\circ} 01^{\prime} \mathrm{E}\right.$; Fig. 1). Aksu City is known as "the Land of Melons and Fruits". It includes municipal total area of $14,300 \mathrm{Km}^{2}$ and built-up area of $28.1 \mathrm{Km}^{2}$.

Aksu City is rich in light and heat resources. It has a long frost-free period from 205 to 219 days. The climate is dry, and rainfall is extremely rare with less than $50 \mathrm{~mm}$ per year and average annual evaporation of $1950 \mathrm{~mm}$. Topography of the study area is flat. The climatic and the physiographic conditions are mostly the same across the region. Therefore, it is an ideal area to explore the relationship between LST and spatial pattern of green space in arid and semi-arid land. 
137 The proportion of green area in the metropolitan region has increased to $30.6 \%$ today from $12 \%$ 138 in early 1980 s. Urban green space coverage has reached $39.2 \%$ with the per capita public green 139 area of $9 \mathrm{~m}^{2}$. Meanwhile, city's ecological environment has been significantly improved. This 140 rapid growth in green space emphasizes a need to develop most effective configuration of green 141 space to reduce the urban heat island caused by expanding impervious surfaces and to adapt to 142 the global climate change.

\section{Methodology}

\subsection{Land Surface Temperature}

Landsat-5 Thematic Mapper (TM) thermal infrared band $6(11.45-12.50 \mu \mathrm{m})$ data with $120 \times$ $120 \mathrm{~m}$ resolution were utilized to derive the LST (Fig. 2b). The satellite data were collected on August 19, 2011, which was a clear day with $0 \%$ cloud cover. Meteorological variables that influence the intensity of urban heat environment at the time of image capture were obtained from China standard meteorological station in the study site. These variables include daily precipitation $(0 \mathrm{~mm})$, daily average wind speed $(1.6 \mathrm{~m} / \mathrm{s})$, wind direction (South-East) and humidity (46\%). Due to the lack of detailed in-situ atmospheric variables that allow physical inversion of brightness temperature to LST, a mono-window algorithm was applied for retrieval of LST (Qin et al., 2001)

$$
T_{S}=\left[a(1-C-D)+(b(1-C-D)+C+D) T_{\text {sensor }}-D T_{a}\right] / C
$$


With $\mathrm{C}=\varepsilon \tau, \mathrm{D}=(1-\tau)[1+(1-\varepsilon) \tau], \alpha=-67.355351$ and $b=0.458606$, where $\varepsilon$ land surface emissivity (LSE) is, $\tau$ is the total atmospheric transmissivity, $T_{\text {sensor }}$ is the at-sensor brightness temperature, and $T_{a}$ represents the mean atmospheric temperature given by:

181 where $\varepsilon_{\text {soil }}$ is the soil emissivity, $\varepsilon_{v e g}$ is the vegetation emissivity, and $d \varepsilon$ includes the effects of 182 the geometry of natural surfaces and the internal reflections. Because most of the study area is a

$$
\begin{aligned}
& \varepsilon=\varepsilon_{\text {soil }}, \text { when NDVI }<0.2, \\
& \varepsilon=\varepsilon_{\text {veg }}, \text { when NDVI }>0.5 \text { and } \\
& \varepsilon=\varepsilon_{\text {veg }} P_{v}+d \varepsilon, \text { when } 0.2 \geq \mathrm{NDVI} \leq 0.5,
\end{aligned}
$$


183 plain surface, this term is negligible. $P_{v}$ is the fraction of the vegetation that can be computed by 184 the following formula (Carlson and Ripley, 1997).

$$
P_{v}=\left[\frac{N D V I-N D V I_{\min }}{\left(N D V I_{\max }-N D V I_{\min }\right)}\right]^{2}
$$

where, $N D V I_{\max }=0.5$, and $N D V I_{\min }=0.2$. Soil and vegetation emissivities were estimated to be 0.97 and 0.99, respectively (Sobrino et al., 2004).

\subsection{Spatial Pattern of Green Space}

The multi-spectral Landsat-5 TM data acquired on August 19, 2011 were used to map green space (i.e., vegetated areas) (Fig. 2a). The spatial resolution of the multispectral data is $30 \mathrm{~m}$. A maximum likelihood image classification approach was applied to extract the vegetated area using ENVI from EXELIS Visual Information Solutions. The four bands green, red, nearinfrared, and two shortwave infrared were used for classification. An accuracy assessment was conducted based on 200 ground reference data that were photo interpreted from existing land cover map with a scale of 1:150000 (produced by Land Resources Bureau of Aksu City and College of Resources and Environmental Sciences, Xinjiang University, China in June, 2012) together with Landsat true color image. The overall accuracy of the derived classification map was $87.60 \%$, and the kappa coefficient was 0.83 (Table 1). 
Insert Figure 2 here

Insert Table 1 here

207 It has been demonstrated that land surface temperature or surface urban heat island could be related to LCLU types (Chen et al., 2006; Connors et al., 2013; Weng, 2001; Xian and Crane, 2006), and there are relationships between spatial structure of urban thermal patterns and urban surface characteristics (Li et al., 2011; Liu and Weng, 2008; Weng et al., 2007). The last several decades have witnessed a remarkable proliferation of studies on developing landscape metrics 1) to characterize landscape patterns and its association to UHIs (Gustafson, 1998; Li and Reynolds, 1993; Li and Wu, 2004; McGarigal and Marks, 1995; Turner, 2005; Turner et al., 1989; Wu, 2000; Wu et al., 2002), and 2) to relate landscape patterns to ecological processes (Turner, 2005). With respect to the measurement objectives, these metrics can be generalized into landscape composition and spatial configuration metrics (Gustafson, 1998; McGarigal and Marks, 1995). Landscape composition metrics measure the presence and amount of different patch types within the landscape without explicitly describing its spatial features while landscape configuration metrics measure the spatial distribution of patches within the landscape (Alberti, 2005). In this study, we selected three commonly occurring landscape metrics to relate LST with spatial pattern of urban green space according to the following principles (Lee et al., 2009; Li and $\mathrm{Wu}, 2004$; Riitters et al., 1995; Riva-Murray et al., 2010): (1) important in both theory and practice, (2) easily calculated, (3) interpretable, and (4) minimal redundancy. Table 2 shows the 224 three landscape metrics. See Mcgarigal et al. (2002) for detailed calculation equation and 225 comments. They are selected to provide complementary information about landscape structure 226 for both composition and configuration. 
Insert Table 2 here

\subsection{Statistical Correlation Measures}

In our case, we used 8-cell rule which considers all eight adjacent cells that share a side with the focal cell and $500 \mathrm{~m}$-radius circular window. The window moves over the 1andscape one cell at a time, calculating the selected metric within the window and returning that value to the center cell and output a new continuous surface grid map for each selected metric (Mcgarigal et al., 2002) . 
Scatter plots were generated to explore the bivariate relationship between LST and each of the landscape metrics. The normalized mutual information measure was assessed based on them (Cover and Thomas, 1991; Webb, 2002). The Shannon entropy of a continuous random variable $X$ with probability density function $p(x)$ for all possible events $\mathrm{x} \in S$ is defined as

$$
H(X)=-\int_{S} p(x) \log p(x) d x
$$

256 where $S$ is the support of the variable and $p(x)$ is its probability distribution function. Probability 257 distributions may be used to construct a frequency distribution of certain events occurring either discretely, in the form of a histogram, or continuously (Allaby, 2008).

260 In the case of a discrete random variable $X$, entropy $H(X)$ is expressed as

264 where $p(x)$ represents the probability of an event $x \in \Omega$ from a finite set $(\Omega)$ of possible values.

variables is a quantity that measures the amount of information that both variables share.

268 Formally, the mutual information of two discrete random variables $X$ and $Y$ can be defined as:

$$
I(X, Y)=\sum_{x \in X} \sum_{y \in Y} p(x, y) \log \left(\frac{p(x, y)}{p(x) p(y)}\right)
$$


where $p(x, y)$ is the joint probability function of $X$ and $Y$, defined as

$$
p(x, y)=P(X=x \& Y=y)
$$

276 We can define:

281 as the marginal probability distribution functions of $X$ and $Y$ respectively.

$282 I(x, y)$ is always a non-negative quantity, being zero when the variables are statistically 283 independent. The higher the value of $I$, the higher is the dependence between them.

285 The normalized mutual information (Cover and Thomas, 1991; Sridhar et al., 1998), can be 286 defined as

$$
C_{X Y}=\frac{I(X ; Y)}{H(Y)} \text { and } C_{Y X}=\frac{I(X ; Y)}{H(X)}
$$

289 This expression can be used as a "correlation" measure (Cover and Thomas, 1991) with the 290 advantage of capturing linear and non-linear relationships among variables. It is sometimes 291 called as "asymmetric dependency coefficient (ADC)" (Sridhar et al., 1998). However, two 
definitions in Eq. (15) will produce unequal values due to their asymmetric property in the definitions. Therefore, a symmetric normalized mutual information measure can be proposed (Press et al., 1990; Strehl and Ghosh, 2003), such as

$$
N I(X, Y)=2 \frac{I(X, Y)}{H(Y)+H(X)}, N I(X, Y)=\frac{I(X, Y)}{\sqrt{H(Y) H(X)}}
$$

297 It is worth mentioning that the mutual information of two random variables $I(X, Y)$ is always 298 smaller than the entropy of any of them, i. e., $H(X)$ or $H(Y)$, namely: $I(X ; Y)<H(Y)$ and $299 I(X ; Y)<H(X)$ are valid, because the information both variables share can never be greater than 300 the information each one has. Therefore $0 \leq C_{X Y} \leq 1$. If $C_{X Y}$ equals one, it means $X, Y$ are

In this study, Eq. 15 was applied to measure the normalized mutual information between the different variables since the focus of the work is to find out the correlation between the land

\section{Results} possibly a park or a nursery with mature grown trees (Fig. 3a). Patch density is high over the

The spatial distribution of PLAND is shown in (Fig. 3a), PD (Fig. 3b) and ED (Fig. 3c). Higher vegetation cover or percent green space is located on the eastern edge of the study site, which is Middle-Western Aksu downtown (Fig. 3b) indicating more fragmented but evenly distributed 
vegetation patches. Edge density, an indicator of linear configuration of green space along the streets, appears to be large on southwest and northeast parts of the study site. The spatial distribution patterns of patch density and edge density are similar suggesting there exists some degree of correlation between these two variables.

Insert Figure 3 here

Two dimensional scatter plots between LST and landscape metrics are shown in Fig. 4. There seems to be a negative linear relationship between LST and both vegetation fraction and edge density. However, these relationships do not seem to be statistically significant enough $\left(R^{2}<\right.$ 0.32 in all cases) to obtain meaningful conclusions. That is why other measures may play an important role. However, some useful information can be extracted. It is interesting to note that patch density and edge density are correlated variables but demonstrates very different degrees of effects on LST. The results imply that edge density has more deterministic effects on LST than the patch density. One may expect that plantation of street trees evenly distributed in the urban area may be an effective way of reducing urban heat island effects, therefore, energy consumption as opposed to establishing dense patches of green space in discrete locations.

Insert Figure 4 here

Table 3 shows the normalized mutual information analysis between the LST and landscape metrics calculated using Eq. (15). It is evident that the compositional and spatial configuration of urban green space can affect the LST to a certain degree. When these two major categories of green space pattern are taken into account separately, it seems the compositional green space 
pattern has slightly larger effect on LST than configurational factors. Meanwhile, the configurational green space patterns do have relatively strong effect but not as strong as compositional green space pattern. The mutual information value was largest when all three landscape metrics were considered in order to see the effect on the LST. This is expected since each of the landscape metrics does have some level of causal interactions with LST change, and the effects could constructively interfere each other. Combination of any two or three of the landscape metrics had a higher impact on LST than that of a single variable. The joint effect of (PLAND, PD) was slightly better in magnitude than the effect of (PLAND, ED) on LST, confirming the stronger correlation between edge density and LST as shown in Fig. 4. However, the mutual information value between $(E D, P D)$ and LST was larger than of the (PLAND, PD) and (PLAND, ED), which might be attributed to the fact that 1) patch density and edge density is more determinative factors that elicits LST, and 2) there exist correlations between patch density and edge density.

Insert Table 3 here

\section{5. Discussion}

352 The results of this study showed that PLAND was correlated with LST with statistical 353 significance. This is consistent with a number of previous studies, which demonstrated negative 354 correlations between LST and the abundance of green space measured by Normalized Difference 355 Vegetation Index (Buyantuyev and $\mathrm{Wu}, 2010$; Chen et al., 2006), fraction of vegetation (Weng et 356 al., 2004), percent cover of LCLU (e.g., Forest, Grass, Cropland, etc.) (Weng et al., 2006; Zhou 357 et al., 2011), or PLAND (Li et al., 2012). Trees and other plants help cool the environment, 358 making green space a simple and effective way to mitigate urban heat island effects. Green 
spaces lower surface and air temperatures by evapotranspiration due to its lower thermal inertia compared to impervious surfaces and bare soils (Hamada and Ohta, 2010; Lambin and Ehrlich, 1996; Weng et al., 2004); by providing shade that prevents land surfaces from direct heating from sunlight (Zhou et al., 2011). Concerning the configurational metrics, the PD and ED were less correlated with LST than PLAND. The normalized mutual information analysis also showed that there was less dependence between the LST with individual PD and ED, which is still smaller than the dependence between the PLAND and LST. This indicates that the increase of patch density leads to a decrease in mean patch size resulting in a general increase in total patch edges. Therefore, the effects of the increase in patch density on LST can be explained by both a decrease in mean patch size and increase in patch edges. The decrease in mean patch size may increase LST because a larger, continuous green space produces stronger cool island effects than that of several small pieces of green space even if whose total area equals to the area of the continuous green space (Cao et al., 2010; Li et al., 2012; Zhang et al., 2009). In contrast, the increase of total patch edges may enhance energy flow and exchange between green space and its surrounding areas, and provide more shade for surrounding surfaces, which lead to the decrease of LST (Zhou et al., 2011).

As far as the each landscape metric is concerned individually, the highest normalized mutual information measure was found with the PLAND (0.71). The implication from this observation is that the composition of green space was more important than the configuration of green space in reducing UHI effects, which is consistent with previous findings (Li et al., 2012; Zhou et al., 2011). However, our results also showed that ED and PD together were the most deterministic factors of LST than the unique effects of a single variable or the joint effects 
PLAND and PD or PLAND and ED. Normalized mutual information measure between LST and PLAND and ED, PLAND and PD and ED and PD were $0.7679,0.7650$ and 0.7832 , respectively. A combination of the three factors PLAND, PD and ED explained much of the variance of LST with a normalized mutual information measure of 0.8694 . This is because the composition and configuration of green space are constructively interrelated.

Many of the results from this study regarding to the relationships between the green space and LST were expected as reported in a number of publications (Connors et al., 2013; Hamada and Ohta, 2010; Li et al., 2011; Weng et al., 2004). Traditionally, increasing the green space by planting more trees has been emphasized in urban planning (Rizwan et al., 2008a; Zhou et al., 2011). While confirming the fact that the increase in green space can significantly mitigate UHI effects, our results showed that configuration of green space as expressed by the joint effect of PD and ED is the most deterministic metric that affects LST. Optimizing the configuration of green space which increases the PD and ED should be highlighted to mitigate UHI effects. These results have important implications for green space management, particularly in rapidly urbanizing arid regions as in our case study, where both water resources and available land area for increased green space is extremely limited.

Under changing climate, arid regions are likely to become even drier, while wet areas tend to get wetter in response to observed global warming (Durack et al., 2012) as indicated by increasing surface temperature. Expanding the urban green space is a rational approach for adapting to climate change. At the same time, it can contribute to the sustainable development of urban areas. However, it may compete with other socio-economic interests that also require space. Therefore, in order to determine a proper balance between the sustainable development and urban green space increase, urban planners should work on optimizing the configuration of 
green space patches in selected areas by increasing the size of existing green space patches rather than building new smaller patches. In the arid Northwestern China, where temperatures are already high and water resources are limited, the outcome of this study can support decisions about sustainable urban design and development, which will help mitigating the effects of future climate, and benefit human wellbeing by improving water and energy use efficiency.

\section{Conclusion}

Taking the urban area of the oasis city of Aksu area as an example, this study quantitatively examined the effects of spatial composition and configuration of green space on land surface temperature (LST). Normalized mutual information measure was used to quantify the relationship between LST and landscape metrics including percentage of landscape (PLAND), edge density (ED) and patch density (PD). Our results showed that 1) both the composition and configuration of green space elicits urban heat island; 2) joint effects of any two combinations of the metrics was larger than the effect of a single metric; 3) ED and PD combined was the most deterministic factor of LST than the unique effects of a single variable or the joint effects PLAND and PD or PLAND and ED; 4) optimizing the configuration of green space which increases the PD and ED should be prioritized in sustainable urban planning and development to mitigate urban heat island effects.

Water scarcity is the major limiting factor of anthropogenic activities in arid and semiarid regions. Specifically, the increase of green space cover is restricted by water availability. 425 Our results suggested that by increasing patch and edge density of the green space, the thermal 426 environment in the City of Aksu can be further improved without expanding the percentage of 427 landscape (PLAND). In arid and semi-arid regions, where temperatures are already high and 
water resources are limited, the outcome of this study may provide climate change adaptation and mitigation benefits by reducing greenhouse gas emissions and energy demand for the cooling of buildings.

\section{Acknowledgments}

434 The first author would like to express his gratitude to the European Commission and Erasmus 435 Mundus Consortium for their important scholarship for master students. We acknowledge the 436 National Natural Science Foundation of China (\#s: 31270742, U1138303, 41130531, 41361016), 437 Sino-German joint research project SuMaRiO (01LL0918C), Research Foundation of Xinjiang University (BS120116 and XY110117) and Education Department of Xinjiang Uygur Autonomous Region (XJEDU2011S07) for financially supporting this work. Finally, we also extend our gratitude to the anonymous reviewers of this manuscript for their helpful suggestions.

\section{References}

Alberti, M., 2005. The effects of urban patterns on ecosystem function. International regional science review 28, 168-192.

Allaby, M., 2008. A Dictionary of Earth Sciences, Third ed. Oxford University Press Inc., New York, pp: 460

Arnfield, A.J., 2003. Two decades of urban climate research: a review of turbulence, exchanges of energy and water, and the urban heat island. International Journal of Climatology 23, 1-26. 
Baker, L.A., Brazel, A.J., Westerhoff, P., 2004. Environmental consequences of rapid urbanization in warm, arid lands: case study of Phoenix, Arizona (USA). In: Marchettini N, Brebbia C, Tiezzi E, Wadhwa LC (eds) The sustainable city III, (Proceedings of the Sienna Conference, held June 2004), Advances in Architecture Series, WIT Press, Boston.

Bowler, D.E., Buyung-Ali, L., Knight, T.M., Pullin, A.S., 2010. Urban greening to cool towns and cities: A systematic review of the empirical evidence. Landscape and Urban Planning $97,147-155$

Buyantuyev, A., Wu, J., 2010. Urban heat islands and landscape heterogeneity: linking spatiotemporal variations in surface temperatures to land-cover and socioeconomic patterns. Landscape ecology 25, 17-33.

Cao, X., Onishi, A., Chen, J., Imura, H., 2010. Quantifying the cool island intensity of urban parks using ASTER and IKONOS data. Landscape and Urban Planning 96, 224-231.

Carlson, T.N., Ripley, D.A., 1997. On the relation between NDVI, fractional vegetation cover, and leaf area index. Remote Sensing of Environment 62, 241-252.

Chen, X.L., Zhao, H.M., Li, P.X., Yin, Z.Y., 2006. Remote sensing image-based analysis of the relationship between urban heat island and land use/cover changes. Remote Sensing of Environment 104, 133-146.

Connors, J.P., Galletti, C.S., Chow, W.T.L., 2013. Landscape configuration and urban heat island effects: assessing the relationship between landscape characteristics and land surface temperature in Phoenix, Arizona. Landscape Ecology, 28, 271-283.

472 Cover, T., Thomas, J., 1991. Elements of Information Theory. Wiley-Interscience. 
Cui, Y.Y., de Foy, B., 2012. Seasonal Variations of the Urban Heat Island at the surface and the near-surface and reductions due to urban vegetation in Mexico City. Journal of Applied Meteorology and Climatology, 51, 855-868.

Dousset, B., Gourmelon, F., 2003. Satellite multi-sensor data analysis of urban surface temperatures and landcover. ISPRS Journal of Photogrammetry and Remote Sensing 58, 43-54.

Durack, P.J., Wijffels, S.E., Matear, R.J., 2012. Ocean Salinities Reveal Strong Global Water Cycle Intensification During 1950 to 2000. Science 336, 455-458.

Fan, P., Qi, J., 2010. Assessing the sustainability of major cities in China. Sustainability Science, $5,51-68$

Feizizadeh, B., Blaschke, T., 2013. Examining urban heat island relations to land use and air pollution: multiple endmember spectral mixture analysis for thermal remote sensing. IEEE Journal of Selected Topics in Applied Earth Observations and Remote Sensing, 6, $1749-1756$.

Gustafson, E.J., 1998. Quantifying landscape spatial pattern: What is the state of the art? Ecosystems 1, 143-156.

Halik, W., Mamat, A., Dang, J.H., Deng, B.S.H., Tiyip, T., 2013. Suitability analysis of human settlement environment within the Tarim Basin in Northwestern China. Quaternary International, 311, 175-180.

Hamada, S., Ohta, T., 2010. Seasonal variations in the cooling effect of urban green areas on surrounding urban areas. Urban forestry \& urban greening 9, 15-24.

Hamdi, R., Schayes, G., 2007. Sensitivity study of the urban heat island intensity to urban characteristics. International Journal of Climatology 28, 973-982. 
Honjo, T., Takakura, T., 1991. Simulation of thermal effects of urban green areas on their surrounding areas. Energy and Buildings 15, 443-446.

Howard, L., 1818. The climate of London, deduced from Meteorological observations, made at different places in the neighbourhood of the metropolis, vol. 2, London, 1818-20.

Huang, G., Zhou, W., Cadenasso, M.L., 2011. Is everyone hot in the city? Spatial pattern of land surface temperatures, land cover and neighborhood socioeconomic characteristics in Baltimore, MD. Journal of Environmental Management, 92,1753-1759.

Imhoff, M.L., Zhang, P., Wolfe, R.E., Bounoua, L., 2010. Remote sensing of the urban heat island effect across biomes in the continental USA. Remote Sensing of Environment $114,504-513$.

James, W., 2002. Green roads: research into permeable pavers. Stormwater 3, 48-40.

Lai, L.-W., Cheng, W.-L., 2009. Air quality influenced by urban heat island coupled with synoptic weather patterns. Science of The Total Environment 407, 2724-2733.

Lambin, E., Ehrlich, D., 1996. The surface temperature-vegetation index space for land cover and land-cover change analysis. International Journal of Remote Sensing 17, 463-487.

Lee, S.-W., Hwang, S.-J., Lee, S.-B., Hwang, H.-S., Sung, H.-C., 2009. Landscape ecological approach to the relationships of land use patterns in watersheds to water quality characteristics. Landscape and Urban Planning 92, 80-89.

Li, H., Reynolds, J.F., 1993. A new contagion index to quantify spatial patterns of landscapes. Landscape ecology 8, 155-162.

Li, H., Wu, J., 2004. Use and misuse of landscape indices. Landscape ecology 19, 389-399. 
Li, J., Song, C., Cao, L., Zhu, F., Meng, X., Wu, J., 2011. Impacts of landscape structure on surface urban heat islands: A case study of Shanghai, China. Remote Sensing of Environment 115, 3249-3263.

Li, X., Zhou, W., Ouyang, Z., Xu, W., Zheng, H., 2012. Spatial pattern of greenspace affects land surface temperature: evidence from the heavily urbanized Beijing metropolitan area, China. Landscape Ecology, 27, 887-898.

Li, X., Zhou W., Ouyang, Z., 2013. Relationship between land surface temperature and spatial pattern of greenspace: What are the effects of spatial resolution? Landscape and Urban Planning, 114, 1-8.

Liu, G., Kurban, A., Duan, H., Halik, Ü., Ablekim, A., Zhang, L. Desert riparian forest colonization in the lower reaches of Tarim River based on remote sensing analysis. Environmental Earth Sciences, DOI: 10.1007/s12665-013-2850-9.

Liu, H., Weng, Q., 2008. Seasonal variations in the relationship between landscape pattern and land surface temperature in Indianapolis, USA. Environmental Monitoring Assessment, $144,199-219$.

Mcgarigal, K., Cushman, S., Neel, M., Ene, E., 2002. FRAGSTATS: spatial pattern analysis program for categorical maps.

McGarigal, K., Marks, B.J., 1995. Spatial pattern analysis program for quantifying landscape structure. Gen. Tech. Rep. PNW-GTR-351. US Department of Agriculture, Forest Service, Pacific Northwest Research Station.

537 Niemelä, J., 1999. Ecology and urban planning. Biodiversity and conservation 8, 119-131.

538 Patz, J.A., Campbell-Lendrum, D., Holloway, T., Foley, J.A., 2005. Impact of regional climate change on human health. Nature 438, 310-317. 
Press, W.H., Flannery, B.P., Teukolsky, S.A., Vetterling, W.T., 1990. Numerical recipes. Cambridge Univ Press.

Pu, R., Gong, P., Michishita, R., Sasagawa, T., 2006. Assessment of multi-resolution and multisensor data for urban surface temperature retrieval. Remote Sensing of Environment 104, 211-225.

Qin, Z.-h., Karnieli, A., Berliner, P., 2001. A mono-window algorithm for retrieving land surface temperature from Landsat TM data and its application to the Israel-Egypt border region. International Journal of Remote Sensing 22, 3719-3746.

Riitters, K.H., O'neill, R., Hunsaker, C., Wickham, J.D., Yankee, D., Timmins, S., Jones, K., Jackson, B., 1995. A factor analysis of landscape pattern and structure metrics. Landscape ecology 10, 23-39.

Riva-Murray, K., Riemann, R., Murdoch, P., Fischer, J.M., Brightbill, R., 2010. Landscape characteristics affecting streams in urbanizing regions of the Delaware River Basin (New Jersey, New York, and Pennsylvania, US). Landscape ecology 25, 1489-1503.

Rizwan, A.M., Dennis, L.Y., Liu, C., 2008a. A review on the generation, determination and mitigation of Urban Heat Island. Journal of Environmental Sciences 20, 120-128.

Rizwan, A.M., Dennis, L.Y.C., Liu, C., 2008b. A review on the generation, determination and mitigation of Urban Heat Island. Journal of Environmental Sciences 20, 120-128.

Sarrat, C., Lemonsu, A., Masson, V., Guedalia, D., 2006. Impact of urban heat island on regional atmospheric pollution. Atmospheric Environment 40, 1743-1758.

Sobrino, J.A., Jiménez-Muñoz, J.C., Paolini, L., 2004. Land surface temperature retrieval from LANDSAT TM 5. Remote Sensing of Environment 90, 434-440. 
Sridhar, D.V., Bartlett, E.B., Seagrave, R.C., 1998. Information theoretic subset selection for neural network models. Computers \& chemical engineering 22, 613-626.

Strehl, A., Ghosh, J., 2003. Cluster ensembles---a knowledge reuse framework for combining

multiple partitions. The Journal of Machine Learning Research 3, 583-617.

Taha, H., 1997. Urban climates and heat islands: albedo, evapotranspiration, and anthropogenic heat. Energy and buildings 25, 99-103.

Tran, H., Uchihama, D., Ochi, S., Yasuoka, Y., 2006. Assessment with satellite data of the urban heat island effects in Asian mega cities. International Journal of Applied Earth Observation and Geoinformation 8, 34-48.

Turner, M.G., 2005. Landscape ecology: what is the state of the science? Annual Review of Ecology, Evolution, and Systematics, 319-344.

Turner, M.G., O'Neill, R.V., Gardner, R.H., Milne, B.T., 1989. Effects of changing spatial scale on the analysis of landscape pattern. Landscape ecology 3, 153-162.

Unger, J., 2004. Intra-urban relationship between surface geometry and urban heat island: review and new approach. Climate research 27, 253-264.

Voogt, J.A., Oke, T., 1998. Effects of urban surface geometry on remotely-sensed surface temperature. International Journal of Remote Sensing 19, 895-920.

Voogt, J.A., Oke, T.R., 2003. Thermal remote sensing of urban climates. Remote sensing of Environment 86, 370-384.

Solecki, W.D., Rosenzweig, C., Parshall, L., Pope, G., Clark, M., Cox, J., Wiencke, M., 2005. Mitigation of the heat island effect in urban New Jersey. Global Environmental Change Part B: Environmental Hazards, 6, 39-49.

Webb, A.R., 2002. Statistical pattern recognition. Wiley. 
Weng, Q., 2001. A remote sensing? GIS evaluation of urban expansion and its impact on surface temperature in the Zhujiang Delta, China. International Journal of Remote Sensing 22, 1999-2014.

Weng, Q., 2009. Thermal infrared remote sensing for urban climate and environmental studies: Methods, applications, and trends. ISPRS Journal of Photogrammetry and Remote Sensing 64, 335-344.

Weng, Q., Liu, H., Lu, D., 2007. Assessing the effects of land use and land cover patterns on thermal conditions using landscape metrics in city of Indianapolis, United States. Urban Ecosystems 10, 203-219.

Weng, Q., Lu, D., Liang, B., 2006. Urban surface biophysical descriptors and land surface temperature variations. Photogrammetric Engineering \& Remote Sensing 72, 1275-1286.

Weng, Q., Lu, D., Schubring, J., 2004. Estimation of land surface temperature-vegetation abundance relationship for urban heat island studies. Remote sensing of Environment 89, 467-483.

Weng, Q., Yang, S., 2006. Urban Air Pollution Patterns, Land Use, and Thermal Landscape: An Examination of the Linkage Using GIS. Environ Monit Assess 117, 463-489.

Wu, C-D., Lung, S-C. C., Jan, J-F., 2013. Development of a 3-D urbanization index using digital terrain models for surface urban heat island effects. ISPRS Journal of Photogrammetry and Remote Sensing, 81, 1-11.

Wu, J., 2000. Landscape ecology: pattern, process, scale and hierarchy. Beijing: Higher Education Press 13, 121-123.

Wu, J., Shen, W., Sun, W., Tueller, P.T., 2002. Empirical patterns of the effects of changing scale on landscape metrics. Landscape Ecology 17, 761-782. 
Xian, G., Crane, M., 2006. An analysis of urban thermal characteristics and associated land cover in Tampa Bay and Las Vegas using Landsat satellite data. Remote Sensing of Environment 104, 147-156.

Yokohari, M., Brown, R.D., Kato, Y., Moriyama, H., 1997. Effects of paddy fields on summertime air and surface temperatures in urban fringe areas of Tokyo, Japan. Landscape and urban planning 38, 1-11.

Zhang, X., Zhong, T., Feng, X., Wang, K., 2009. Estimation of the relationship between vegetation patches and urban land surface temperature with remote sensing. International Journal of Remote Sensing 30, 2105-2118.

Zhao, C., Fu, G., Liu, X., Fu, F., 2011. Urban planning indicators, morphology and climate indicators: A case study for a north-south transect of Beijing, China. Building and Environment 46, 1174-1183.

Zhou, W., Huang, G., Cadenasso, M.L., 2011. Does spatial configuration matter? Understanding the effects of land cover pattern on land surface temperature in urban landscapes. Landscape and Urban Planning 102, 54-63. 
Tables:

632 Table 1 Accuracy assessment of the urban green space classification map

633 Table 2 Landscape metrics used in this study(Mcgarigal et al., 2002)

634 Table 3 Normalized mutual information results of compositional configuration of green space 635 and landscape metrics

639 Fig. 1. Location map of the study area showing overview map of China (top - left corner) and 640 the Xinjiang Uyghur Autonomous Region (bottom-left corner).

Fig. 2. Green space and LST maps for the downtown are Aksu city: (a) green space map, and (b) LST map with units of Kelvin

Fig. 3. Grid map of urban green space metrics (a) Percent cover of green space (b) Patch density (c) Edge density

Fig. 4. Scatter plot of LST with PLAND, PD and ED 


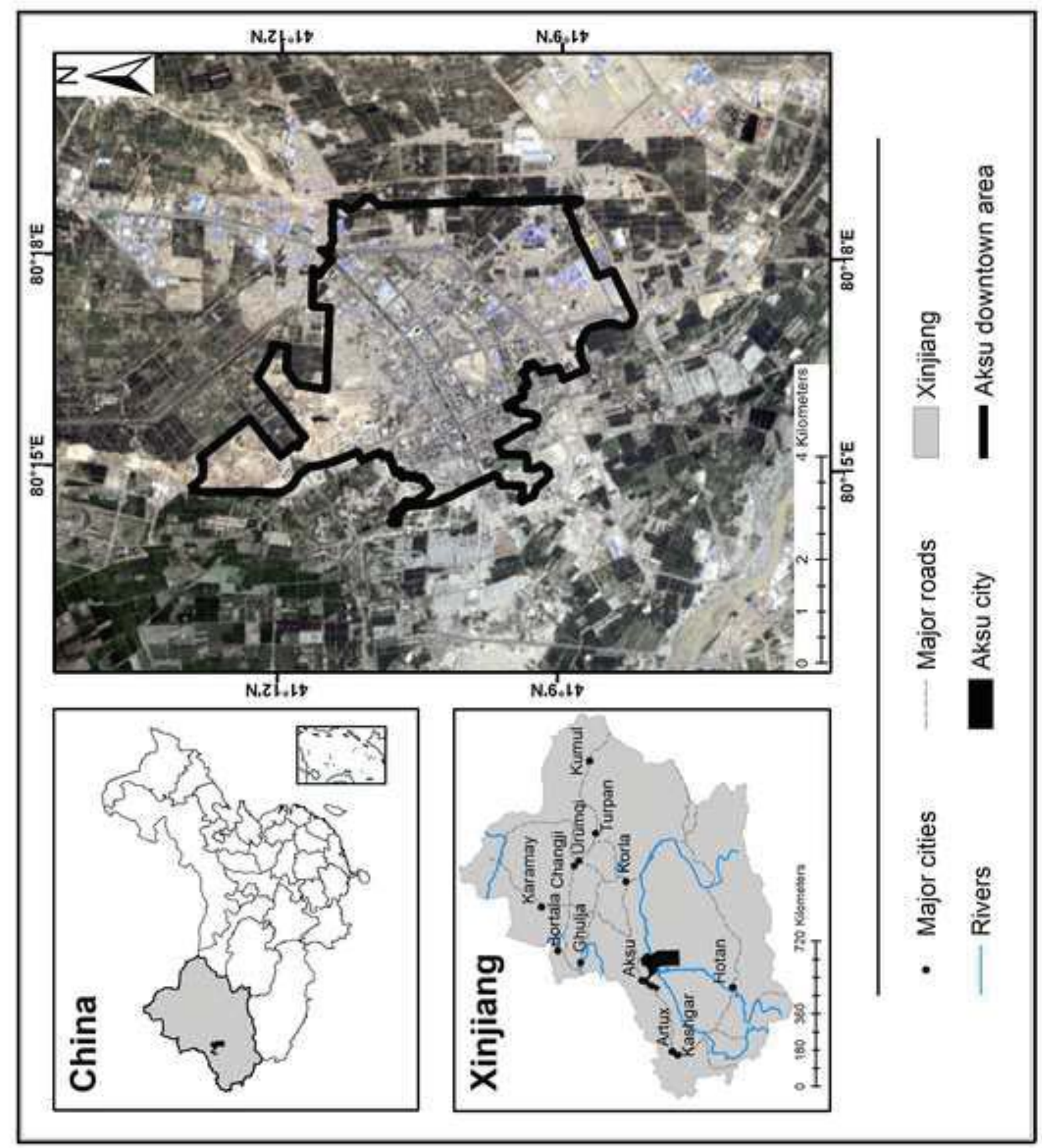




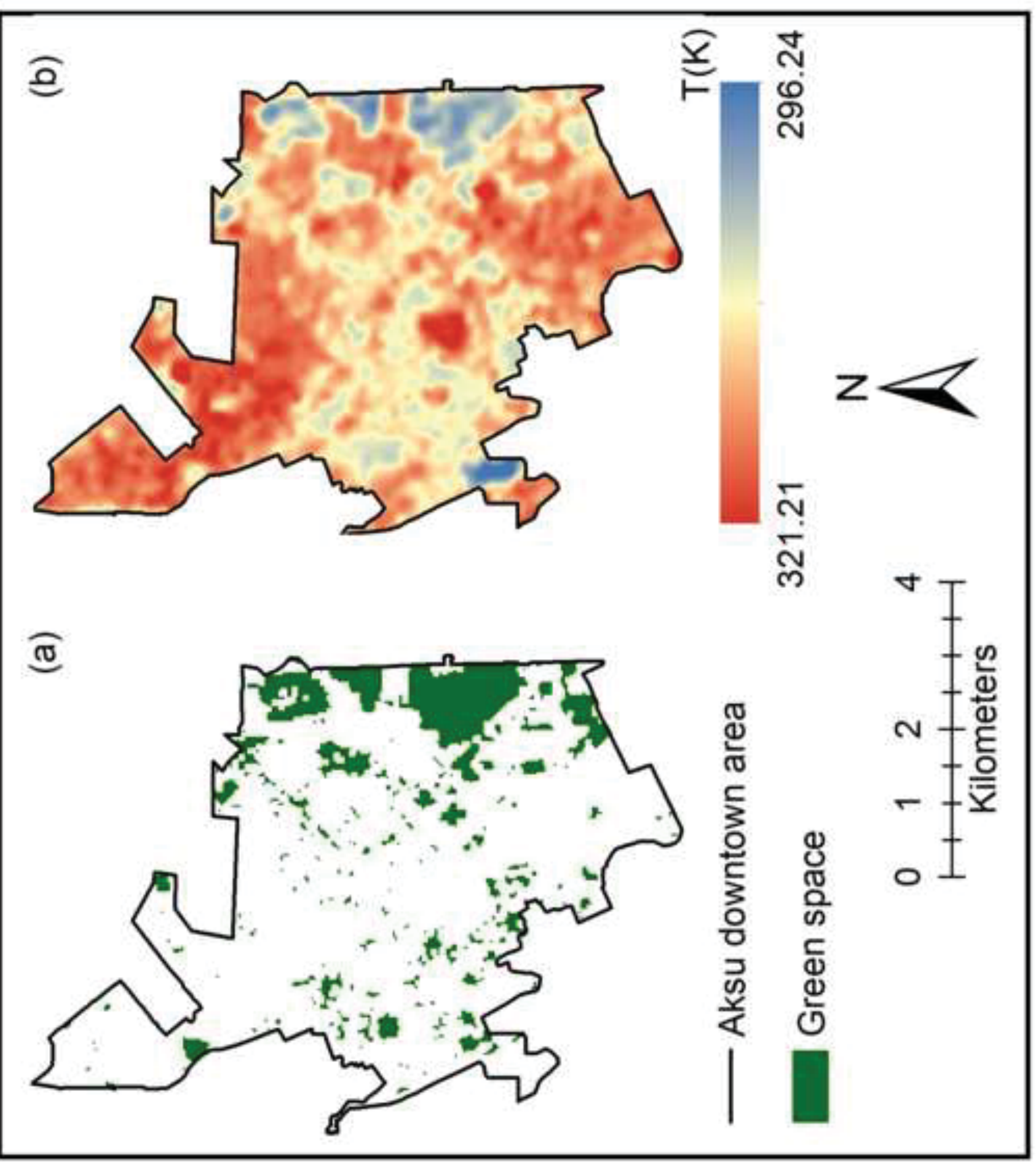




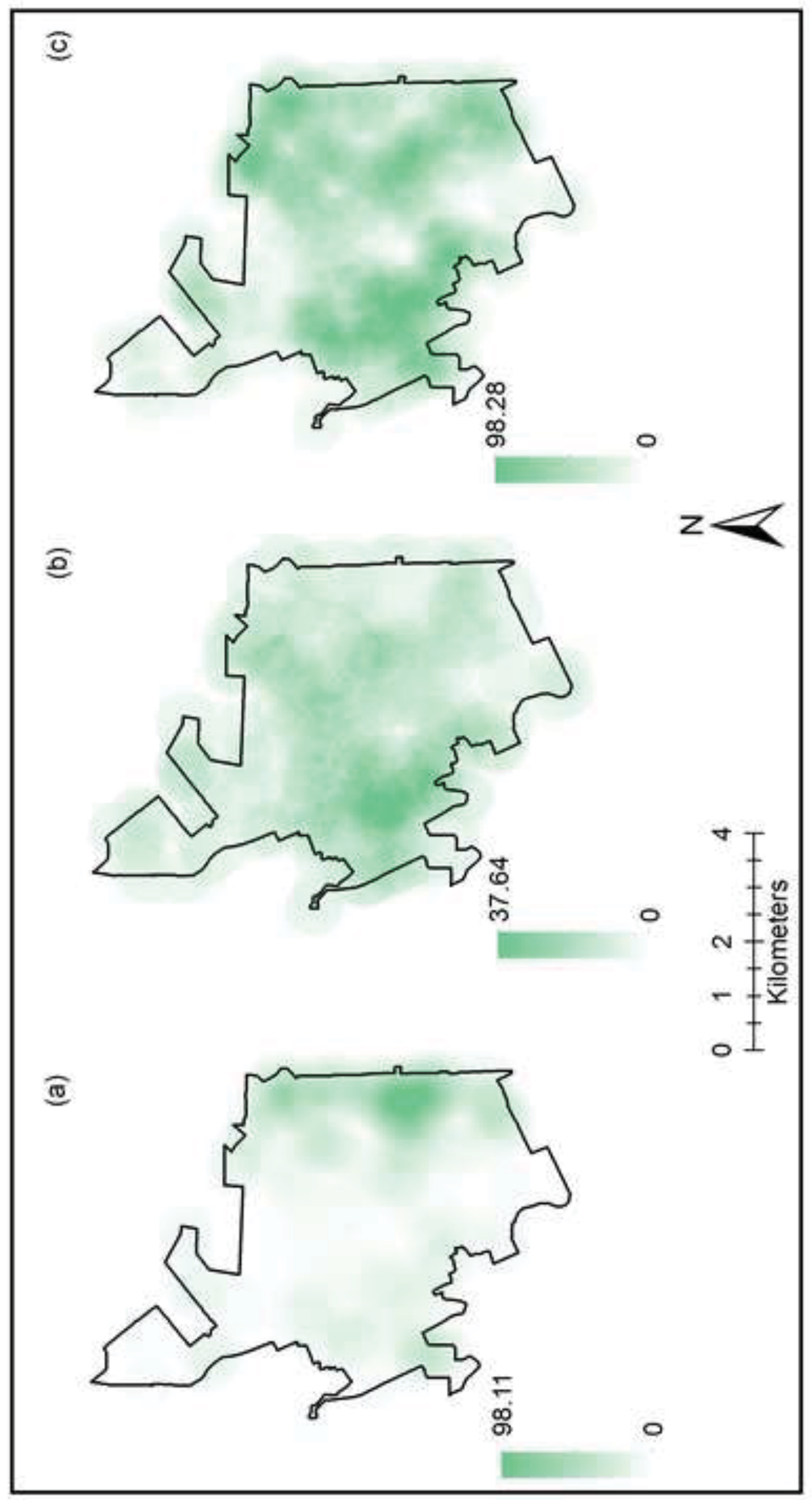

$m$ 이

可证 

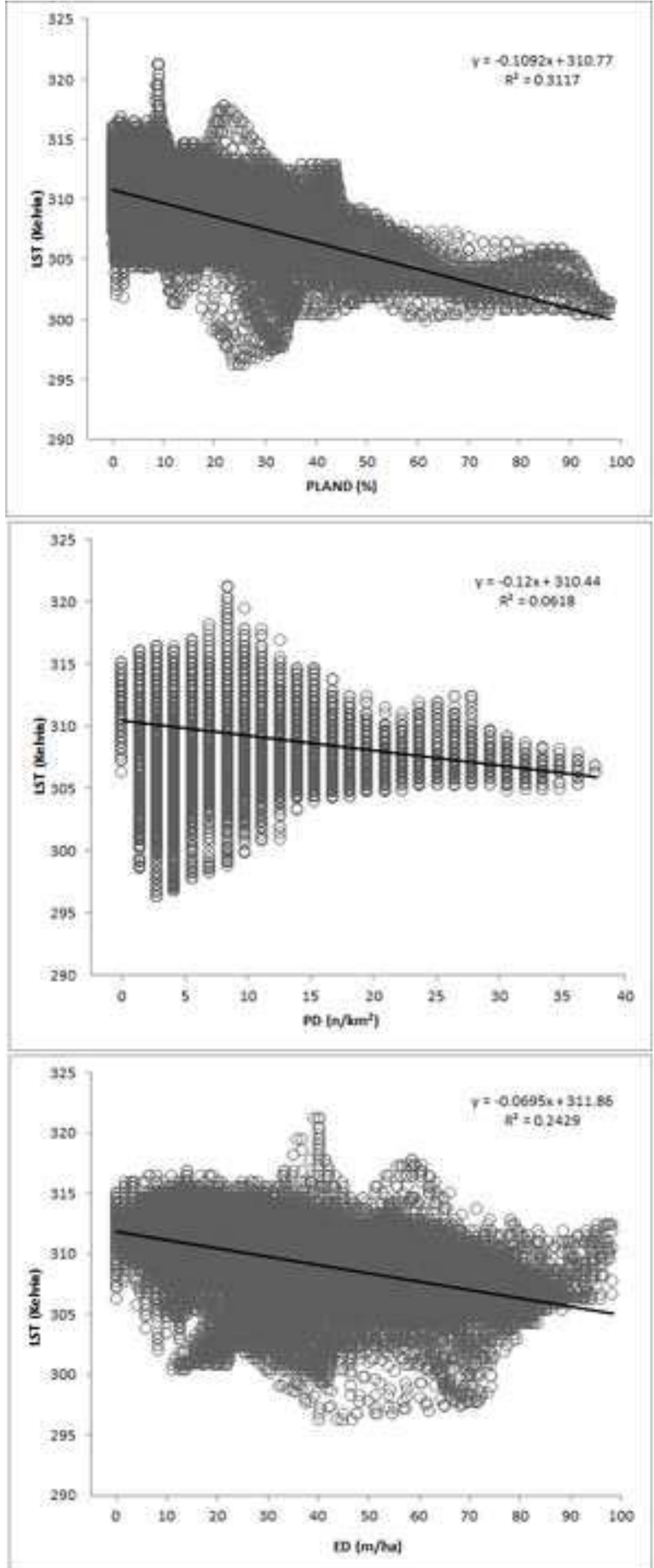
Click here to download Table: Table 1 Accuracy assessment of the urban green space derived map.docx

Table 1 Accuracy assessment of the urban green space classification map.

\begin{tabular}{|c|c|c|c|c|c|c|}
\hline & \multicolumn{5}{|c|}{ Reference data (Pixels) } & \multirow[b]{2}{*}{$\begin{array}{c}\text { User's } \\
\text { accuracy }(\%\end{array}$} \\
\hline & $\begin{array}{c}\text { Urban } \\
\text { green space }\end{array}$ & $\begin{array}{l}\text { Residential } \\
\text { area }\end{array}$ & $\begin{array}{c}\text { Construction } \\
\text { site }\end{array}$ & $\begin{array}{l}\text { Water } \\
\text { body }\end{array}$ & Total & \\
\hline Urban green space & 231 & 6 & 2 & 2 & 241 & 95.9 \\
\hline Residential area & 0 & 170 & 15 & 2 & 187 & 90.9 \\
\hline Construction site & 1 & 53 & 148 & 2 & 202 & 73.3 \\
\hline Water body & 0 & 11 & 0 & 99 & 110 & 90.0 \\
\hline Total & 232 & 240 & 165 & 103 & 740 & \\
\hline Producer's accuracy (\%) & 99.6 & 70.8 & 89.7 & 96.1 & & \\
\hline Overall Accuracy (\%) & 87.6 & & & & & \\
\hline Kappa coefficient & 0.83 & & & & & \\
\hline
\end{tabular}


Click here to download Table: Table 2 Landscape metrics used in this study.docx

Table 2 Landscape metrics used in this study(Mcgarigal et al., 2002)

\section{Metrics (abbreviation)}

Compositional

Percentage of Landscape (PLAND)

\section{Configurational}

Patch density(PD)

Edge density(ED)
Calculation and description

$$
100 / A \times \sum_{i=1}^{n} a_{i}
$$

Proportional abundance of green space in the

$$
\text { landscape }(\%)
$$

$$
n / A \times 10^{6}
$$

Number of green space patches divided by

total landscape area $\left(\mathrm{n} / \mathrm{km}^{2}\right)$

$$
10,000 / A \times \sum_{i=1}^{n} e_{i}
$$

Total length (border not included) of all edge segments of green space per hectare $(\mathrm{m} / \mathrm{ha})$

$a_{i}$ area of patch $i ; e_{i}$ length of edge (or perimeter) of patch $i ; A$ landscape area; $n$ number of patches 
Click here to download Table: Table 3 Normalized mutual information results of compositional configuration of green space anc

Table 3 Normalized mutual information results of compositional configuration of green space and landscape metrics

\begin{tabular}{ccc}
\hline & $C_{X Y}$ & $\begin{array}{c}\text { Normalized mutual information } \\
\text { value }\end{array}$ \\
\hline PLAND & $Y$ & 0.7100 \\
PD & & 0.6985 \\
ED & & 0.7033 \\
PLAND, PD & LST & 0.7679 \\
PLAND, ED & & 0.7650 \\
PD, ED & 0.7832 \\
PLAND, PD,ED & 0.8694 \\
\hline
\end{tabular}

